\title{
Prepolymerization of Lacquer Sap under Pure Oxygen Atmosphere and Its Effects on the Properties of Lacquer Film
}

\author{
Jianhong Yang, Jianfeng Zhu, Wanghui Liu, Jianping Deng, and Yuanyuan Ding \\ Department of Environmental Engineering, School of Environmental and Safety Engineering, Changzhou University, \\ Changzhou, Jiangsu 213164, China \\ Correspondence should be addressed to Jianhong Yang; yangjianhong@cczu.edu.cn
}

Received 10 February 2015; Revised 20 May 2015; Accepted 25 May 2015

Academic Editor: T. Yoshida

Copyright (c) 2015 Jianhong Yang et al. This is an open access article distributed under the Creative Commons Attribution License, which permits unrestricted use, distribution, and reproduction in any medium, provided the original work is properly cited.

\begin{abstract}
A series of lacquer saps were prepared by prepolymerization under oxygen atmosphere. The prepolymerization process was investigated by GPC, UV-Vis, FT-IR, NMR, and microscope. The results showed that the polymerization of urushiol monomer was accelerated. The content of monomer in the lacquer sap swiftly decreased from $82.68 \%$ to $47.75 \%$ in $0.5 \mathrm{~h}$. The mechanism of polymerization was complex and was involved in the coupling reaction of phenyl ring, the addition reaction of the unsaturated carbon-carbon double bond groups with urushiol hydroxyl groups, and other reactions that occurred on the side chains. In addition, the prepolymerization also improved significantly the drying property of lacquer film, especially at low relative humidity. At the same time, the sizes of the water drops in the lacquer saps significantly decreased with increasing the stirring time and the surface of lacquer film became smoother, which resulted in its excellent gloss (109-125). Due to the prepolymerization, the pencil hardness and the thermal stability of lacquer film were slightly improved as well.
\end{abstract}

\section{Introduction}

Lacquer sap, a kind of water-in-oil (W/O) type emulsion, is collected from lac trees grown mainly in China and Japan (Rhus vernicifera), Vietnam and Chinese Taiwan (Rhus succedanea), and Burma and Thailand (Melanorrhoea usitata) $[1,2]$. The sap of lac tree $R$. vernicifera consists of complex components including urushiol (60 65\%), laccase $(\sim 0.2 \%)$, gummy substance $(5 \sim 7 \%)$, glycoprotein $(\sim 2 \%)$, and water (20 30\%) [3]. The lacquer sap has been used as coatings in China and Japan for thousands of years [4]. A red wooden bowl is the known earliest lacquer ware, which was found at Hemudu site in Zhejiang Province of China. It was made more than 7000 years ago $[3,5]$. Today, lacquer sap is still interesting due to its natural ecofriendly feature and the excellent physicochemical properties of its film such as anticorrosiveness, high thermal stability, good brilliance, and superhigh durability [6-9]. However, lacquer sap dries by the oxidative polymerization of urushiol catalyzed by laccase under a specific condition (about 70 90\% relative humidity at $20 \sim 30^{\circ} \mathrm{C}$ ), which is followed by an autoxidation reaction on the long aliphatic unsaturated side chain as well [2, 4, 10-14].
This strict drying condition has prevented its use as an industrial paint [1].

Recently, many methods have been developed to improve the drying property of lacquer sap. A UV irradiation method had been used to promote the drying of lacquer sap, but it severely damaged some properties of lacquer film such as gloss and durability [15]. A lacquer with a decrease of the urushiol monomer had also been prepared using a repeated kurome process by stirring with additional moisture in the reaction vessel. The kurome lacquer dried quickly in a natural environment due to prepolymerization of urushiol [10]. Some hybrid lacquers were also developed based on the kurome lacquer, such as lacquer/polyurethane-hybrid lacquer and lacquer/organic silane-hybrid lacquer [3, 16-18], but the process of repeated kurome needs to take a long time and only very small amount of fast drying lacquer could be obtained. In addition, it is well known that $\mathrm{O}_{2}$ is essential for the oxidation polymerization of urushiol [1921]. Thus, the fast drying lacquer should also be able to be prepared under oxygen atmosphere. $\mathrm{Li}$ et al. prepared some refined lacquers under oxygen atmosphere at $20^{\circ} \mathrm{C}$. However, it was surprising that these lacquers did not dry 
[22]. So far, further study has not been done to investigate the polymerization of lacquer sap under pure oxygen atmosphere and the properties of the polymerized lacquer. In this paper, we aim to accelerate the drying of lacquer film through the prepolymerization of lacquer sap under pure oxygen atmosphere. The polymerization mechanism of lacquer sap was studied by GPC, UV-Vis, FT-IR, and NMR methods. Some properties of the prepolymerized lacquer films were investigated as well.

\section{Materials and Methods}

2.1. Materials. The raw lacquer sap collected from lac tree R. vernicifera in China was purchased from Lichuan Delong Co., Ltd. (Enshi, China). The lacquer, a neat filtered sap, has naturally high moisture content of $26.9 \%$. All other chemicals were of analytical grade and were used as received.

2.2. Prepolymerization of Lacquer Sap. Raw lacquer sap $(100 \mathrm{~g})$ was polymerized in a closed four-neck reaction flask $(250 \mathrm{~mL})$ equipped with a mechanic stirrer, reflux condenser, thermometer, and oxygen inlet. The lacquer sap was stirred with the rate of $240 \mathrm{rmp}$ at $30^{\circ} \mathrm{C}$ under 1 atm oxygen atmosphere. A series of samples were prepared by controlling the prepolymerization time from $0.5 \mathrm{~h}$ to $3.0 \mathrm{~h}$. Similarly, under the condition of air instead of pure oxygen, a series of samples were also prepared.

2.3. Drying Property. The raw and prepolymerized lacquer saps were applied on glass plate using $50 \mu \mathrm{m}$ film applicators (Tianjin Jingke Material Equipment Co., Ltd., China) and dried at different relative humidity $(\mathrm{RH})$ in a 302 A temperature damp-heat regulation chamber (Shanghai Laboratory Instrument Works Co., Ltd., China) and their drying time was evaluated by QGZ-24 automatic drying time recorder (Tianjin Jingke Material Equipment Co., Ltd., China). The process of lacquer drying can be divided into two steps: touch-free dryness (TD) and hardened dryness (HD). The time until the marks of needle appear on the film surface is equivalent to TD, and the time until the marks of needle disappear completely on the lacquer film surface is equivalent to HD [10].

2.4. Pencil Hardness Test. The pencil hardness was checked on previously degreased tinplate with a dry film (thickness of the wet coating $50 \mu \mathrm{m}$ ). Panels were subjected to property evaluation after two weeks of cure at $30^{\circ} \mathrm{C}$ and $80 \%$ RH. Pencil hardness was determined according to current national standard of GB/T6739-2006.

2.5. Characterization. The molecular weight of sample was measured by a gel permeation chromatography (GPC) on a LC-20AD instrument (Shimadzu, Japan) equipped with a TSK G3000- $\mathrm{H}_{\mathrm{XL}}$ column (TOSOH, Japan). The eluent was THF. The flow rate was $1.0 \mathrm{~mL} / \mathrm{min}$. The temperature of the column was maintained at $30^{\circ} \mathrm{C}$. The eluate was monitored with RID-10A refractive index detector (Shimadzu, Japan). The standards used for calibration the column were polystyrene. All data provided by the GPC system were collected and analyzed with the aid of the LCsolution Workstation software package.

The UV-Vis spectra were recorded on a SPECORD 50 spectrophotometer (Analytik Jena AG, Germany). The sample was thinly spread on the quartz plate.

FT-IR spectra were recorded on a Nicolet Avatar 370 FTIR spectrometer (Thermo, Madison, USA). The samples were thinly applied on the $\mathrm{KBr}$ pellets. 32 scans at a resolution of $2 \mathrm{~cm}^{-1}$ were averaged and referenced against air.

${ }^{1} \mathrm{H}$ NMR spectra were recorded on a Bruker AVANCE III $400 \mathrm{MHz}$ NMR spectrometer (Switzerland) with tetramethylsilane (TMS) as the internal standard. The samples were dissolved in $\mathrm{CDCl}_{3}$.

The micrographs of lacquer saps were observed by a BX 43 microscope (Olympus, Japan) and obtained using a digital camera (ToupCam, China).

The surface morphologies of lacquer films were examined using a scanning electron microscope (SEM) Zeiss SUPRA55 (Germany).

The thermal behavior of lacquer film was estimated using a NETZSCH TG 209 F3 apparatus (Germany). The TG oven was programmed from $48^{\circ} \mathrm{C}$ to $647^{\circ} \mathrm{C}$ under $\mathrm{N}_{2}$ atmosphere, a rise of $10^{\circ} \mathrm{C} / \mathrm{min}$. The lacquer film (thickness of the wet coating $50 \mu \mathrm{m}$ ) was dried at $30^{\circ} \mathrm{C}$ and $80 \% \mathrm{RH}$ for one week.

The gloss of lacquer film was tested with an XGP20 $60^{\circ}-85^{\circ}$ specular gloss meter (Tianjin Xintongguangda Technology Co., Ltd., China). Lacquer films were prepared with $50 \mu \mathrm{m}$ thickness of the wet coating on tinplate panels and evaluated after two weeks of cure at $30^{\circ} \mathrm{C}$ and $80 \% \mathrm{RH}$.

\section{Results and Discussion}

\subsection{Prepolymerization of Lacquer Sap}

3.1.1. Molecular Weight Change in the Polymerization Process. The molecular weight distribution of the lacquer saps was monitored by GPC in the polymerization process under oxygen atmosphere and air atmosphere, respectively. The results are summarized in Table 1 . It can be seen from Table 1 that the contents of urushiol monomer, oligomer, and polymer were $82.68 \%, 17.23 \%$, and $0.09 \%$ in the raw lacquer, respectively. Under oxygen atmosphere, the urushiol monomer decreased rapidly to $47.75 \%$ in the prepolymerized lacquers and the oligomer increased quickly to $48.61 \%$ in the initial half an hour, indicating that the oxidation polymerization of urushiol was very fast. With increasing the reaction time from $0.5 \mathrm{~h}$ to $3.0 \mathrm{~h}$, the content of urushiol monomer only decreased slowly from $47.75 \%$ to $23.28 \%$. The polymerization of urushiol monomer became slow, which could mainly be due to the increase of the viscosity of prepolymerized lacquers. At the same time, a prominent feature was also observed in which the polymer increased swiftly from $3.64 \%$ to $20.48 \%$, while the oligomer changed within the scope of $48.61-58.62 \%$. Compared with the polymerization of urushiol under oxygen atmosphere, the conversion of urushiol monomer was very slow under air atmosphere. The contents of urushiol monomer, oligomer, and polymer were 
TABLE 1: The molecular weight distribution of the raw and the prepolymerized lacquer saps under different atmospheres.

\begin{tabular}{lccccccc}
\hline \multirow{2}{*}{ Sample } & \multirow{2}{*}{ Prepolymerization time } & \multicolumn{3}{c}{ Oxygen atmosphere } & \multicolumn{3}{c}{$\begin{array}{c}\text { Air atmosphere } \\
\text { Oligomer/\% }\end{array}$} \\
& & Polymer/\% & Oligomer/\% & Monomer/\% & Polymer/\% & Moner/\% \\
\hline $\mathrm{RL}^{\mathrm{a}}$ & $0 \mathrm{~h}$ & 0.09 & 17.23 & 82.68 & 0.09 & 17.23 & 82.68 \\
1 & $0.5 \mathrm{~h}$ & 3.64 & 48.61 & 47.75 & 0.50 & 28.29 & 71.21 \\
2 & $1.0 \mathrm{~h}$ & 4.66 & 58.32 & 37.02 & 0.63 & 31.44 & 67.93 \\
3 & $1.5 \mathrm{~h}$ & 7.10 & 55.35 & 37.55 & 0.88 & 32.87 & 66.25 \\
4 & $2.0 \mathrm{~h}$ & 10.95 & 58.62 & 30.43 & 1.08 & 33.34 & 65.58 \\
5 & $2.5 \mathrm{~h}$ & 15.84 & 54.38 & 29.78 & 1.10 & 34.17 & 64.73 \\
6 & $3.0 \mathrm{~h}$ & 20.48 & 56.24 & 23.28 & 1.51 & 37.85 & 60.64 \\
\hline
\end{tabular}

${ }^{\mathrm{a}}$ Raw lacquer; ${ }^{\mathrm{b}}$ polymer: $M_{w} \geq 3000$; oligomer: $3000>M_{w} \geq 640$; monomer: $M_{w}<640$.

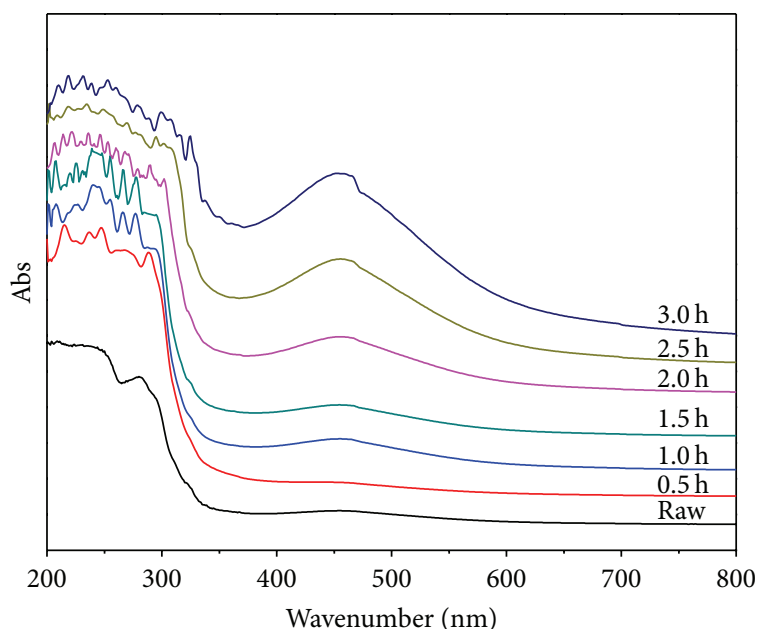

FIGURE 1: UV-Vis spectra of the raw lacquer sap and the prepolymerized lacquer saps.

only $60.64 \%, 37.85 \%$, and $1.51 \%$ until $3.0 \mathrm{~h}$, respectively. All the results suggested that the condition with pure oxygen atmosphere was advantageous to accelerate the polymerization of urushiol monomer. It is well known that the oxidation polymerization of urushiol is mainly catalyzed by laccase. The laccase contains four copper atoms and catalyzes the reduction of $\mathrm{O}_{2}$ at a trinuclear copper cluster. $\mathrm{O}_{2}$ is essential for the oxidation polymerization of urushiol [19-21]. Under pure oxygen atmosphere, the fully reduced form of laccase could adequately contact $\mathrm{O}_{2}$ and quickly react with $\mathrm{O}_{2}$ to produce the intermediate with an oxygen-radical bound to the trinuclear copper cluster and oxidized the substrates into the products [19]. Thus, the laccase catalyzed polymerization of urushiol was accelerated under pure oxygen condition.

3.1.2. UV-Vis Spectra. The prepolymerization process of the lacquer sap under oxygen atmosphere was monitored with a UV-Vis spectrophotometer. Figure 1 shows the UV-Vis spectra of the raw lacquer sap and prepolymerized lacquer saps. In the UV-Vis spectrum of raw lacquer, the broad peak at $200-265 \mathrm{~nm}$ was due to the $\pi-\pi^{*}$ of conjugated alkadiene ( $\mathrm{K}$ band), and the peak at $280 \mathrm{~nm}$ was due to the $\pi-\pi^{*}$ of phenyl of urushiol (B band) [23]. In the oxidation polymerization process of lacquer sap, the $\mathrm{K}$ band became broad and overlapped the $\mathrm{B}$ band. In the meantime, the

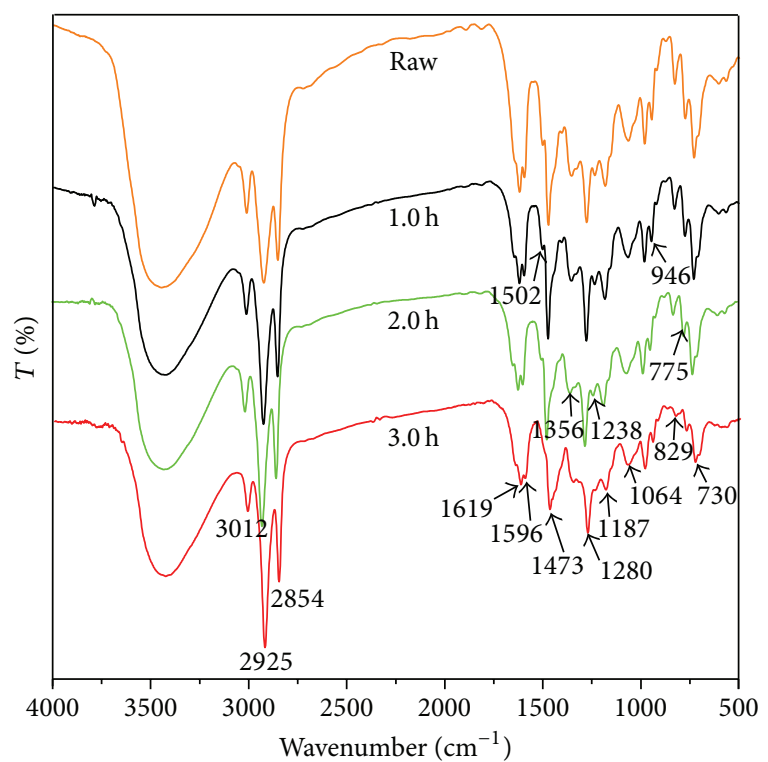

FIGURE 2: FT-IR spectra of the raw lacquer sap and the prepolymerized lacquer saps.

B band also shifted toward the red end of the spectrum. These indicated that the polymerization of urushiol occurred to form a bigger conjugated structure. In addition, a new band at about $450 \mathrm{~nm}$ was also observed, which also resulted from the absorption of the molecules with large conjugated structure. The intensity of the band increased gradually in the polymerization process, indicating that the extent of conjugation increased.

3.1.3. FT-IR and NMR Spectra. The prepolymerization process of the lacquer sap under oxygen atmosphere was also analyzed with FT-IR and NMR spectrophotometers. Figure 2 shows the FT-IR spectra of the raw and the prepolymerized lacquer saps. The peaks at 1356,1280 , and $1187 \mathrm{~cm}^{-1}$ were due to $\beta \mathrm{O}-\mathrm{H}, \gamma \mathrm{O}-\mathrm{H}$, and $\mathrm{C}-\mathrm{O}$ vibration of $\mathrm{C}-\mathrm{O}-\mathrm{H}$ group [24], respectively. In the spectra of the prepolymerized lacquer saps, their intensities decreased gradually with the increase of prepolymerization time, suggesting that the $\mathrm{O}-\mathrm{H}$ groups on the phenyl ring participated in the polymerization reaction. A peak at $3012 \mathrm{~cm}^{-1}$ was related to $\mathrm{C}-\mathrm{H}$ vibration of the phenyl ring [9]. Its intensity decreased with increasing 


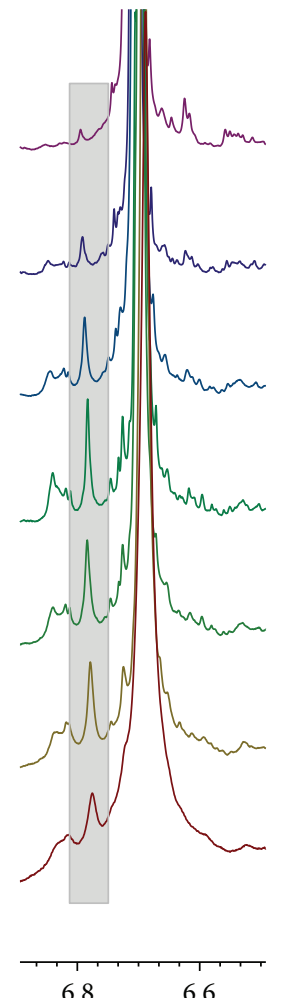

$6.8-6.6$

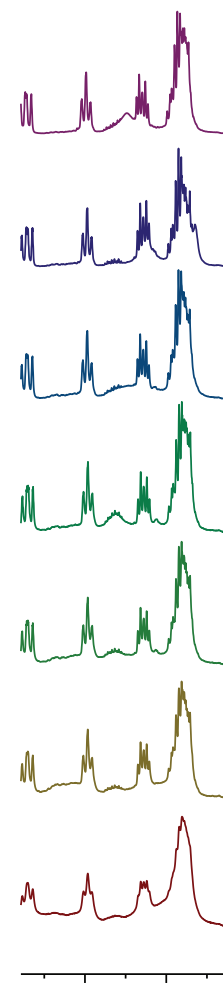

6.0
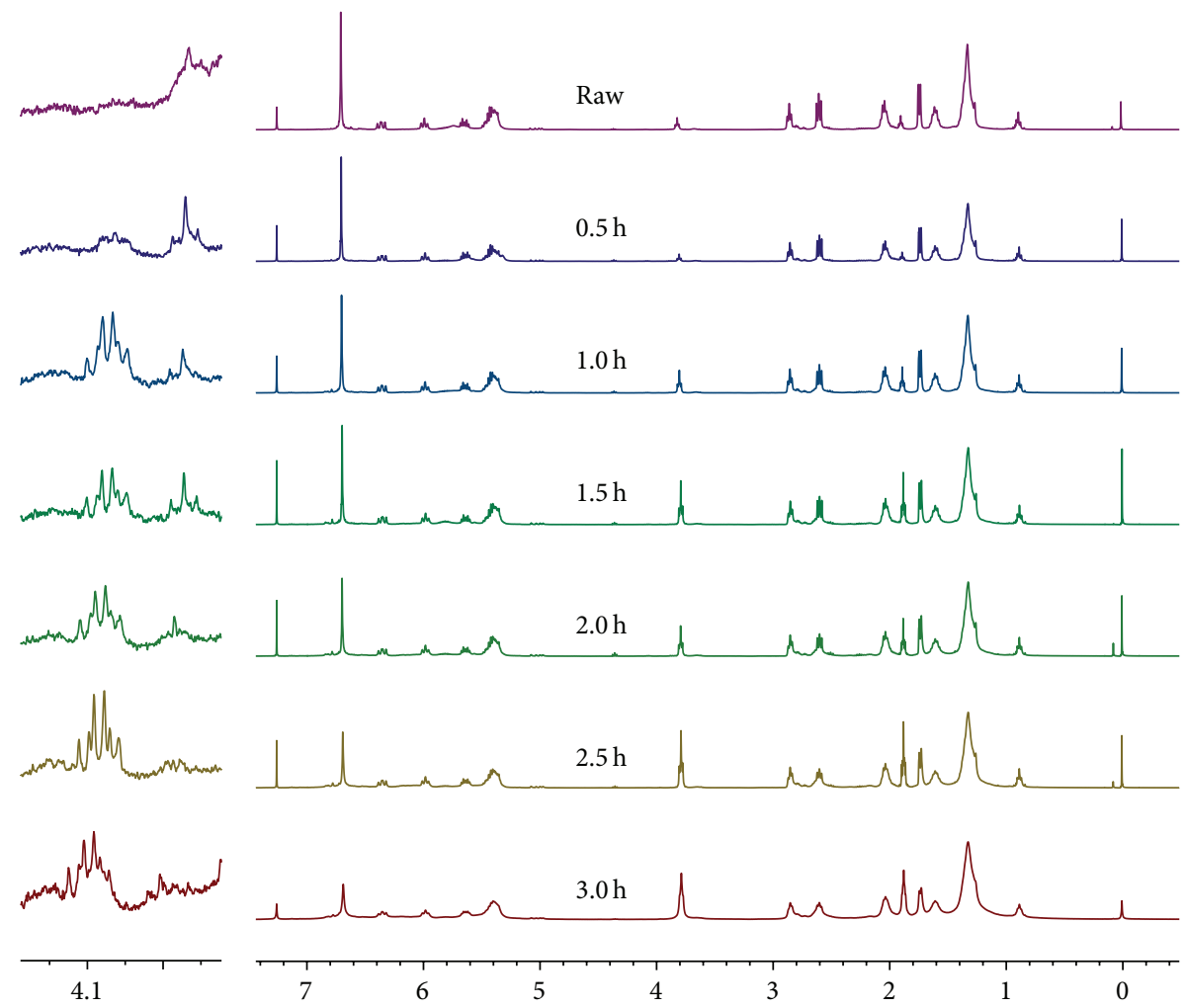

FIGURE 3: ${ }^{1} \mathrm{H}$ NMR spectra of the raw lacquer saps and the prepolymerization lacquer saps in $\mathrm{CDCl}_{3}$.

the prepolymerization time, and the peaks at $775 \mathrm{~cm}^{-1}$ also became weak, suggesting that more substitution occurred on the phenol ring [14]. Furthermore, the peaks at 946 and $983 \mathrm{~cm}^{-1}$ due to the conjugated dienes obviously decreased [15], and the peak at $983 \mathrm{~cm}^{-1}$ shifted to $987 \mathrm{~cm}^{-1}$ in $3 \mathrm{~h} \mathrm{of}$ prepolymerized lacquer sap as well [24], indicating that some reactions occurred not only on the phenol rings, but also in the side chains.

${ }^{1} \mathrm{H}$ NMR spectra of the raw and prepolymerized lacquer saps are shown in Figure 3. The peak at about $6.71 \mathrm{ppm}$ is assigned to the ${ }^{1} \mathrm{H}$ signal on the phenyl ring, and the peak at $6.78 \mathrm{ppm}$ is due to the ${ }^{1} \mathrm{H}$ signal of the biphenyl $[25,26]$. The integral value of the former gradually decreased with increasing the reaction time from 0 to $3.0 \mathrm{~h}$, but the value of the latter increased, suggesting that more substitutions occurred on the phenyl rings, and the polymerization is involved in the oxidative coupling reaction of urushiol molecules as well. The peaks at 5.15-5.55 ppm were assigned to the protons of the $-\mathrm{C}-\mathrm{CH}=\mathrm{CH}-\mathrm{C}-$ in the side chain [10]. Their integral values gradually decreased, suggesting that some reactions also occurred on the side chain. In addition, some new peaks that appeared at $4.05-4.20 \mathrm{ppm}$ could be assigned to the proton of the $-\mathrm{C}=\mathrm{C}-\mathrm{C}-\mathrm{CH}-\mathrm{O}-\mathrm{Ph}[10]$, indicating that the addition reaction of the unsaturated carbon-carbon double bond groups in the side chain with urushiol hydroxyl groups had occurred in the polymerization process too.

3.1.4. Micrograph. Figure 4 shows the micrographs of the raw and the prepolymerized lacquer saps. Raw lacquer sap is a kind of natural water-in-oil (W/O) type emulsion. It can be seen from the micrographs of raw lacquer sap that the water was dispersed in the oil phase and the diameter of water drops was in the scope of $0.5-10 \mu \mathrm{m}$. The distribution of the size of water drops was broad. In the prepolymerization process, as the lacquer sap was continuously stirred, the sizes of water drops gradually decreased and their distribution was also more homogeneous as shown in Figure 4. The sizes of water drops were $0.5-3.0 \mu \mathrm{m}$ after $3 \mathrm{~h}$. In the meantime, the color of lacquer saps also changed gradually. For the raw lacquer sap, the color of its oil was gray and the color of its water drops was light blue-purple in the microscope. After $3 \mathrm{~h}$ of prepolymerization, the color of the water drops was still maintained basically, but the color of the oil became deep yellow. It could be related to the polymerization extent of urushiol. The intensity of the band of the prepolymerized lacquer sap at about $450 \mathrm{~nm}$ increased gradually in the polymerization process as mentioned in the UV-Vis spectra, which led to the change of its color [27].

\subsection{Properties and Characterization of Lacquer Film}

3.2.1. Drying and Coating Properties. The drying time and the coating properties such as gloss and pencil hardness of the raw lacquer sap and the prepolymerized lacquer saps are shown in Table 2. It can be seen from Table 2 that the drying time of the raw lacquer to reach touch-free dryness and hardened dryness was $3 \mathrm{~h} 20 \mathrm{~min}$ and $5 \mathrm{~h} 50 \mathrm{~min}$ at a high relative humidity of $78 \%$. Compared with the raw lacquer, the prepolymerized lacquers dried faster and the drying time 


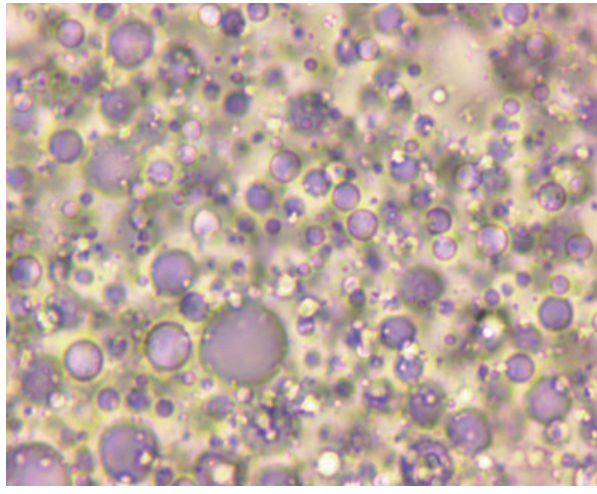

(a)

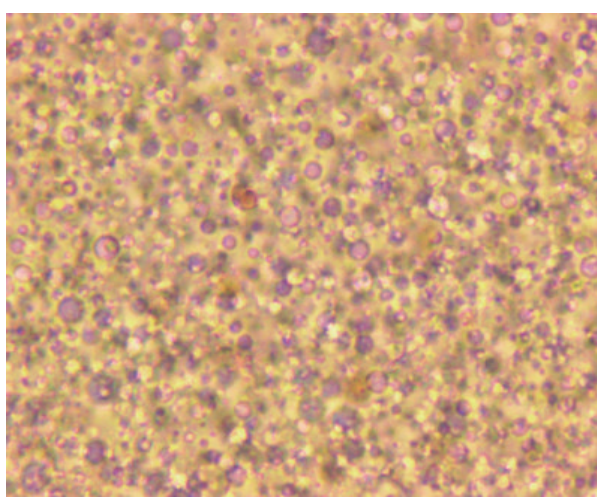

(c)

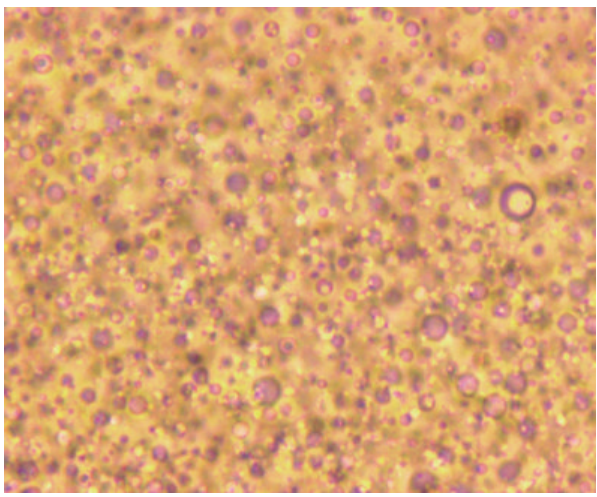

(e)

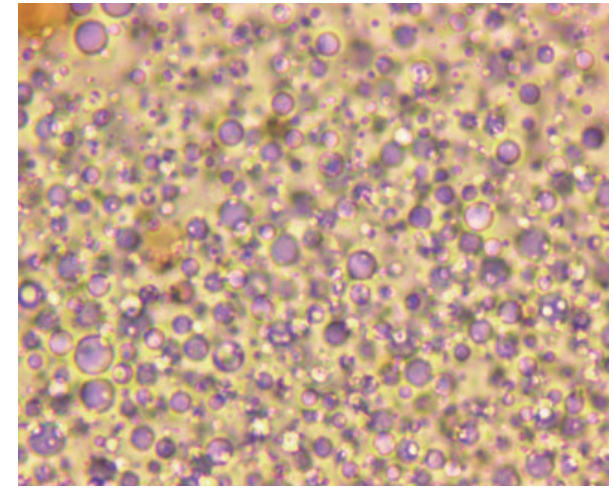

(b)

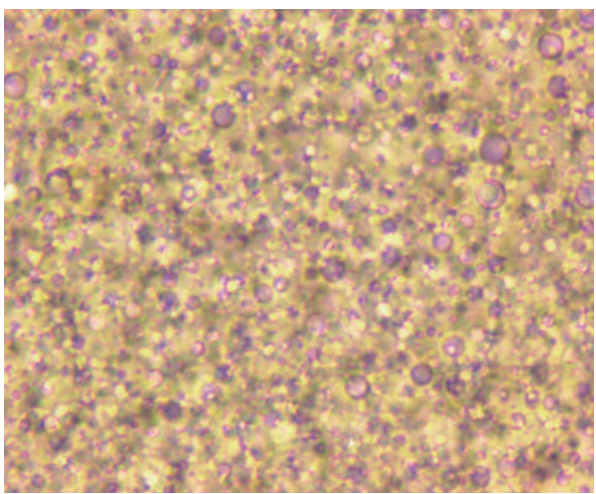

(d)

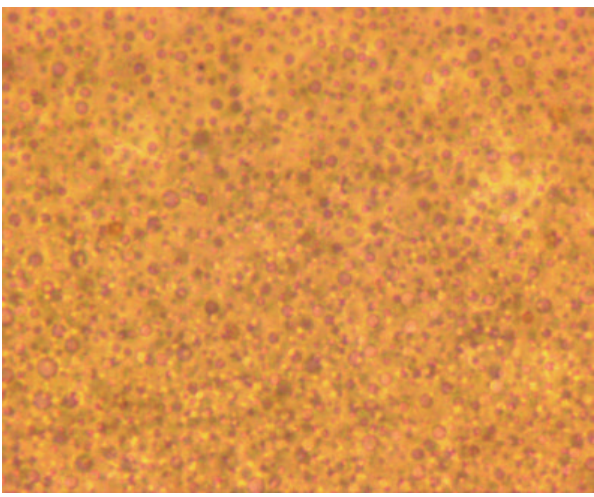

(f)

Figure 4: Micrographs (1000x magnification) of raw lacquer saps in different prepolymerization time. (a) 0 h; (b) 0.5 h; (c) $1.0 \mathrm{~h}$; (d) $1.5 \mathrm{~h}$; (e) $2.5 \mathrm{~h}$; (f) $3.0 \mathrm{~h}$.

TABLE 2: Drying time (h:min) of lacquer films and coating properties of cured films.

\begin{tabular}{|c|c|c|c|c|c|c|c|}
\hline \multirow{2}{*}{ Sample } & \multirow{2}{*}{ Prepolymerization time $(\mathrm{h})$} & \multicolumn{2}{|c|}{$30^{\circ} \mathrm{C}, 78 \% \mathrm{RH}$} & \multicolumn{2}{|c|}{$30^{\circ} \mathrm{C}, 65 \% \mathrm{RH}$} & \multirow{2}{*}{ Pencil hardness ${ }^{b}$} & \multirow{2}{*}{ Gloss ${ }^{b}$} \\
\hline & & TD & $\mathrm{HD}$ & $\mathrm{TD}$ & $\mathrm{HD}$ & & \\
\hline $\mathrm{RL}^{\mathrm{a}}$ & 0 & $3: 20$ & $5: 50$ & $23: 30$ & $30: 20$ & $3 \mathrm{H}$ & 81 \\
\hline 1 & $0.5 \mathrm{~h}$ & $2: 30$ & $4: 30$ & $18: 10$ & $26: 20$ & $4 \mathrm{H}$ & 119 \\
\hline 2 & $1.0 \mathrm{~h}$ & $2: 30$ & $4: 00$ & $11: 20$ & $18: 40$ & $4 \mathrm{H}$ & 118 \\
\hline 3 & $1.5 \mathrm{~h}$ & $2: 20$ & $3: 30$ & $9: 50$ & $17: 10$ & $4 \mathrm{H}$ & 115 \\
\hline 4 & $2.0 \mathrm{~h}$ & $1: 30$ & $2: 50$ & $8: 50$ & $15: 10$ & $4 \mathrm{H}$ & 125 \\
\hline 5 & $2.5 \mathrm{~h}$ & $0: 30$ & $2: 30$ & $6: 40$ & $13: 20$ & $4 \mathrm{H}$ & 109 \\
\hline 6 & $3.0 \mathrm{~h}$ & $0: 40$ & $2: 20$ & $5: 40$ & $12: 30$ & $4 \mathrm{H}$ & 110 \\
\hline
\end{tabular}

${ }^{\mathrm{a}} \mathrm{RL}$ : raw lacquer; ${ }^{\mathrm{b}}$ the lacquer films were tested after drying at $30^{\circ} \mathrm{C}$ and $80 \% \mathrm{RH}$ for two weeks. 


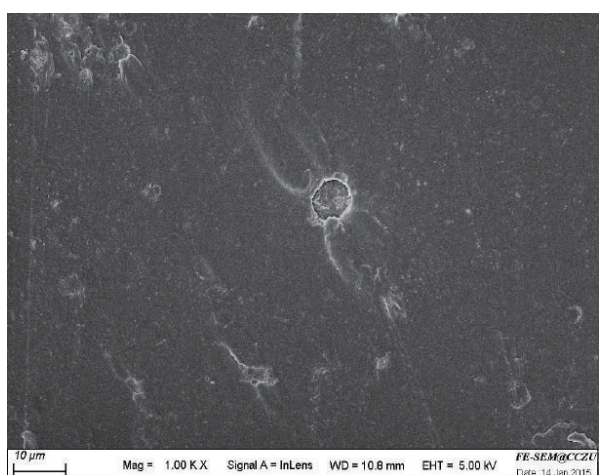

(a)

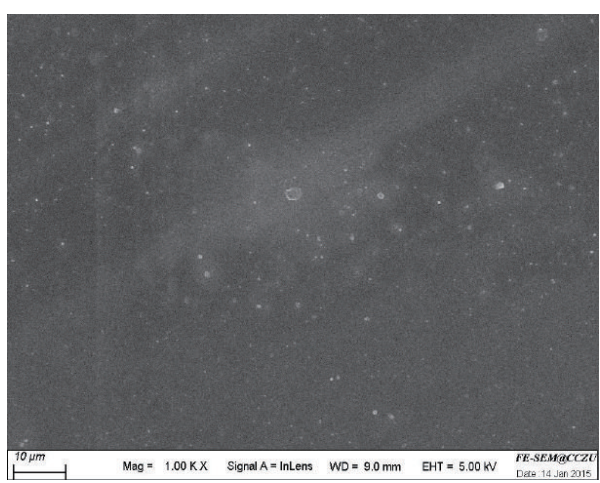

(c)

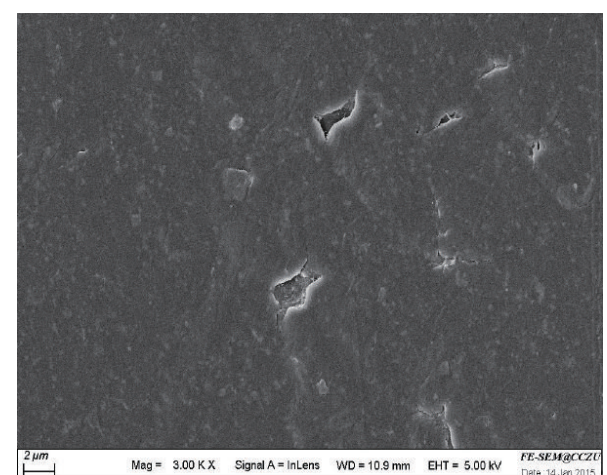

(b)

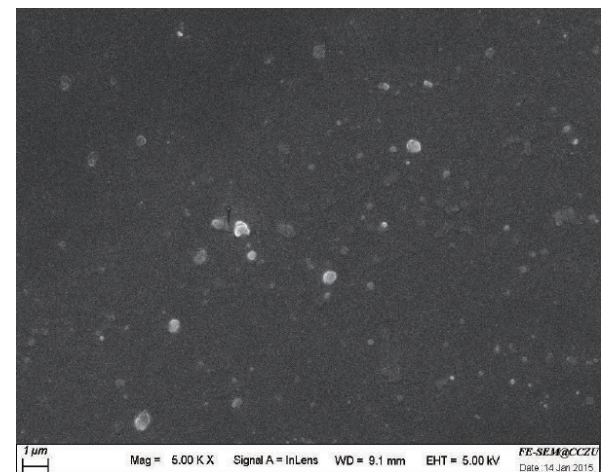

(d)

FIGURE 5: SEM photographs of the raw lacquer film ((a) magnification: $1.00 \mathrm{Kx}$; (b) magnification: $3.00 \mathrm{Kx})$ and the prepolymerization lacquer film after $3.0 \mathrm{~h}$ ((c) magnification: $1.00 \mathrm{Kx}$; (d) magnification: $5.00 \mathrm{Kx}$ ).

gradually decreased with the increase of prepolymerization time. When the prepolymerization time was $3.0 \mathrm{~h}$, the drying time of sample's film to reach TD and HD was $40 \mathrm{~min}$ and $2 \mathrm{~h} 20 \mathrm{~min}$, respectively. Moreover, the drying time of the raw lacquer to reach TD and HD greatly increased at low relative humidity of $65 \%$ and was $23 \mathrm{~h} 30 \mathrm{~min}$ and $30 \mathrm{~h} 20 \mathrm{~min}$, respectively. However, for the prepolymerized lacquer saps, their drying time was much shorter than that of lacquer sap. After the lacquer sap was prepolymerized for $3.0 \mathrm{~h}$, its drying time of TD and HD was only $5 \mathrm{~h} 40 \mathrm{~min}$ and $12 \mathrm{~h} 30 \mathrm{~min}$ correspondingly. Obviously, the prepolymerization of lacquer sap could improve significantly the drying property, especially at low relative humidity. Furthermore, from the data shown in Table 2, it was also observed that the pencil hardness of the prepolymerized lacquer films slightly increased from $3 \mathrm{H}$ to $4 \mathrm{H}$. However, the gloss of lacquer films was markedly improved by the prepolymerization of lacquer sap. The gloss of the raw lacquer film was 81 , but that of all prepolymerized lacquer films was higher and within the scope of 109-125. It could be because the prepolymerization of lacquer sap resulted in the decrease of the water drops' sizes as mentioned previously in the micrographs.

3.2.2. SEM. The surface morphologies of the raw lacquer and its prepolymerized lacquer films were analyzed with a SEM, and their SEM images are shown in Figure 5. It was observed that there were some "caves" in the raw lacquer film, which resulted from the evaporation of water in the drying process $[10,24]$. The diameters of the "caves" were about $0.2-5 \mu \mathrm{m}$ (Figures 5(a) and 5(b)). Due to the caves, the surface of the raw lacquer film was not very smooth. For the prepolymerized lacquer film, some "caves" were also observed. But their sizes were smaller $(<0.5 \mu \mathrm{m})$, which was due to the smaller diameters of water drops in the lacquer sap (Figures 5(c) and 5(d)). Compared with the raw lacquer film, the surface of the prepolymerized lacquer film was smoother as well. The gloss of the lacquer films was closely related to their surface smoothness [24]. Obviously, the excellent gloss of the prepolymerized lacquer films resulted from their good surface smoothness.

3.2.3. Thermal Analysis. The TG curves of the raw and prepolymerized lacquer films are shown in Figure 6. The degradation of the raw lacquer film could be divided into three stages. The first stage of raw lacquer film at $48-220^{\circ} \mathrm{C}$ with the weight loss of $3.28 \%$ was due to the loss of water and other small molecules. Its second degradation stage started at $220^{\circ} \mathrm{C}$ till $420^{\circ} \mathrm{C}$ with weight loss of $28.62 \%$, which stemmed from the decomposition of lacquer polysaccharide, glycoprotein, and urushiol monomer [13]. The third stage began at $420^{\circ} \mathrm{C}$ till $647^{\circ} \mathrm{C}$ with weight loss of $52.58 \%$ that was attributed to the degradation of urushiol oligomer and polymer. Compared with the raw lacquer film, the prepolymerized lacquer films had similar TG curves. However, their weight loss was less 


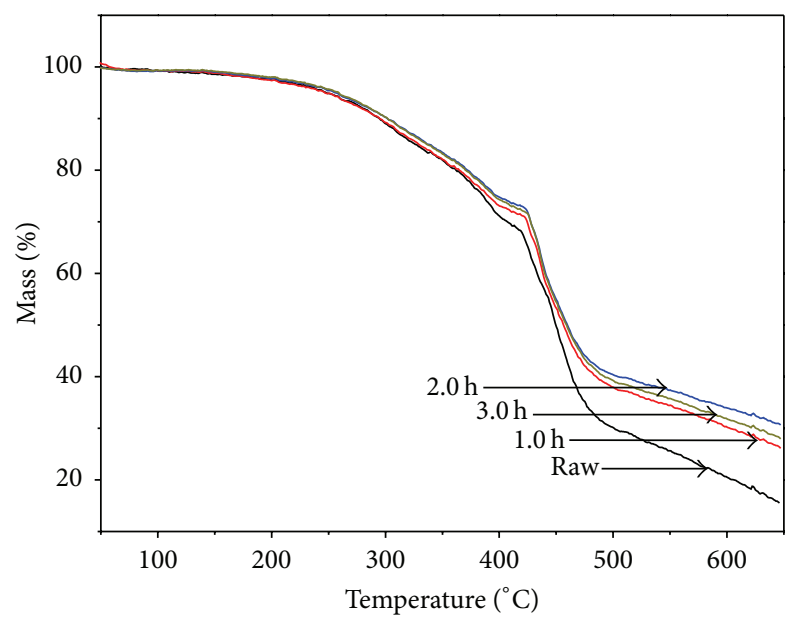

Figure 6: TG and DTG curves of the raw and the prepolymerized lacquer films.

after $200^{\circ} \mathrm{C}$. At $647^{\circ} \mathrm{C}$, the weight loss of raw lacquer film was $84.48 \%$ while that of the prepolymerized lacquer films was in the range from $69.38 \%$ to $75.07 \%$. It indicated that the prepolymerized lacquer films possessed higher thermal stability, which could be because the extent of polymerization of lacquer films was improved after the prepolymerization of lacquer sap.

\section{Conclusion}

In this study, the raw lacquer sap was prepolymerized under oxygen atmosphere. The polymerization rate was quicker than that under air atmosphere. 59.4\% of urushiol monomer was converted into the oligomer and polymer in $3.0 \mathrm{~h}$. The polymerization of urushiol was complex, which was involved in the coupling reaction of phenyl ring, the addition reaction of the unsaturated carbon-carbon double bonds with urushiol hydroxyl groups, and other reactions that occurred on the side chains. Due to the prepolymerization, the drying time of lacquer sap was shortened greatly, especially at the low relative humidity. In addition, the thermal stability of lacquer film was improved, and its gloss also became very excellent. Thus, the prepolymerization of lacquer sap under oxygen atmosphere is to hopefully be used to prepare a fast drying lacquer on a large scale and promote the applications of lacquer sap as an industrial paint.

\section{Conflict of Interests}

The authors declare that there is no conflict of interests regarding the publication of this paper.

\section{Acknowledgment}

This work was supported by the National Natural Science Foundation of China Grant no. 31270616.

\section{References}

[1] J. Kumanotani, "Urushi (oriental lacquer)—a natural aesthetic durable and future-promising coating," Progress in Organic Coatings, vol. 26, no. 2-4, pp. 163-195, 1995.

[2] R. Lu, T. Yoshida, and T. Miyakoshi, "Oriental lacquer: a natural polymer," Polymer Reviews, vol. 53, no. 2, pp. 153-191, 2013.

[3] R. Lu, Y.-Y. Wan, T. Honda, T. Ishimura, Y. Kamiya, and T. Miyakoshi, "Design and characterization of modified urethane lacquer coating," Progress in Organic Coatings, vol. 57, no. 3, pp. 215-222, 2006.

[4] J. Kumanotani, "Enzyme catalyzed durable and authentic oriental lacquer: a natural microgelprintable coating by polysaccharide-glycoprotein-phenolic lipid complexes," Progress in Organic Coatings, vol. 34, no. 1-4, pp. 135-146, 1997.

[5] W. Bai, L. Cai, D. Zhou et al., "Resurrection of dead lacquerCupric potassium chloride dihydrate $\left(\mathrm{K}_{2} \mathrm{CuCl}_{4} \cdot 2 \mathrm{H}_{2} \mathrm{O}\right)$ used as the mimic laccase," Progress in Organic Coatings, vol. 77, no. 2, pp. 431-438, 2014.

[6] H. Langhals and D. Bathelt, "The restoration of the largest archaelogical discovery-a chemical problem: conservation of the polychromy of the Chinese Terracotta Army in Lintong," Angewandte Chemie International Edition, vol. 42, no. 46, pp. 5676-5681, 2003.

[7] N. Niimura and T. Miyakoshi, "Structural study of oriental lacquer films during the hardening process," Talanta, vol. 70, no. 1, pp. 146-152, 2006.

[8] H. S. Kim, J. H. Yeum, S. W. Choi, J. Y. Lee, and I. W. Cheong, "Urushiol/polyurethane-urea dispersions and their film properties," Progress in Organic Coatings, vol. 65, no. 3, pp. 341-347, 2009.

[9] J. Xia, J. Lin, Y. Xu, and Q. Chen, "On the UV-induced polymeric behavior of chinese lacquer," ACS Applied Materials and Interfaces, vol. 3, no. 2, pp. 482-489, 2011.

[10] R. Lu, S. Harigaya, T. Ishimura, K. Nagase, and T. Miyakoshi, "Development of a fast drying lacquer based on raw lacquer sap," Progress in Organic Coatings, vol. 51, no. 3, pp. 238-243, 2004.

[11] J. K. Agbenyega, M. Claybourn, and G. Ellis, "A study of the autoxidation of some unsaturated fatty acid methyl esters using Fourier transform Raman spectroscopy," Spectrochimica Acta Part A: Molecular Spectroscopy, vol. 47, no. 9-10, pp. 1375-1388, 1991.

[12] A. I. Yaropolov, O. V. Skorobogat'ko, S. S. Vartanov, and S. D. Varfolomeyev, "Laccase properties, catalytic mechanism, and applicability," Applied Biochemistry and Biotechnology, vol. 49, no. 3, pp. 257-280, 1994.

[13] A. M. Mayer and R. C. Staples, "Laccase: new functions for an old enzyme," Phytochemistry, vol. 60, no. 6, pp. 551-565, 2002.

[14] J. Kumanotani, K. Inoue, M. Achiwa, and L. W. Chen, "Behavior of water in oriental lacquers," Polymer Science and Technology, vol. 33, pp. 163-176, 1986.

[15] J. Xia, Y. Xu, J. Lin, and B. Hu, "UV-induced polymerization of urushiol without photoinitiator," Progress in Organic Coatings, vol. 61, no. 1, pp. 7-10, 2008.

[16] R. Lu, T. Ishimura, K. Tsutida, T. Honda, and T. Miyakoshi, "Development of a fast drying hybrid lacquer in a low-relativehumidity environment based on kuromelacquer sap," Journal of Applied Polymer Science, vol. 98, no. 3, pp. 1055-1061, 2005.

[17] R. Lu, T. Moteki, and T. Miyakoshi, "Development and characterization of micro-dispersed lacquer," Journal of Chinese Lacquer, vol. 29, no. 1, pp. 1-5, 2010. 
[18] T. Ishimura, R. Lu, K. Yamasaki, and T. Miyakoshi, "Effects of hybridization of lacquer sap with organic silane on drying properties," Progress in Organic Coatings, vol. 62, no. 2, pp. 193198, 2008.

[19] S.-K. Lee, S. D. George, W. E. Antholine, B. Hedman, K. O. Hodgson, and E. I. Solomon, "Nature of the intermediate formed in the reduction of $\mathrm{O}_{2}$ to $\mathrm{H}_{2} \mathrm{O}$ at the trinuclear copper cluster active site in native laccase," Journal of the American Chemical Society, vol. 124, no. 21, pp. 6180-6193, 2002.

[20] N. Hakulinen, L.-L. Kiiskinen, K. Kruus et al., "Crystal structure of a laccase from Melanocarpus albomyces with an intact trinuclear copper site," Nature Structural Biology, vol. 9, no. 8, pp. 601-605, 2002.

[21] N. Aktaş, H. Çiçek, A. Taşpnar Ünal, G. Kibarer, N. Kolankaya, and A. Tanyolaç, "Reaction kinetics for laccase-catalyzed polymerization of 1-naphthol," Bioresource Technology, vol. 80, no. 1, pp. 29-36, 2001.

[22] X. Li, Y. Shi, and F. Zhang, "Research on the influencing factors of lacquer refining process," Journal of Chinese Lacquer, vol. 25, no. 2, pp. 6-10, 2006.

[23] X. Zheng, J. Weng, Q. Huang, B. Hu, T. Qiao, and P. Deng, "Fabrication of a stable poly(vinylpyrrolidone)/poly(urushiol) multilayer ultrathin film through layer-by-layer assembly and photo-induced polymerization," Colloids and Surfaces A: Physicochemical and Engineering Aspects, vol. 337, no. 1-3, pp. 15-20, 2009.

[24] J. Yang, J. Deng, Q. Zhang, Q. Shen, D. Li, and Z. Xiao, "Effects of polysaccharides on the properties of Chinese lacquer sap," Progress in Organic Coatings, vol. 78, pp. 176-182, 2015.

[25] S. Harigaya, T. Honda, L. Rong, T. Miyakoshi, and C.-L. Chen, "Enzymatic dehydrogenative polymerization of urushiols in fresh exudates from the lacquer tree, Rhus vernicifera DC," Journal of Agricultural and Food Chemistry, vol. 55, no. 6, pp. 2201-2208, 2007.

[26] M. Takada, R. Oshima, Y. Yamauchi, J. Kumanotani, and M. Seno, "Coupling reactions of 4-tert-butyl-o-benzoquinone with olefinic compounds," The Journal of Organic Chemistry, vol. 53, no. 13, pp. 3073-3080, 1988.

[27] D. L. Pavia, G. M. Lamoman, G. S. Kriz, and J. R. Vyvyan, Introduction to Spectroscopy, Brooks/Cole Cengage Learning, Belmont, Tenn, USA, 4th edition, 2009. 

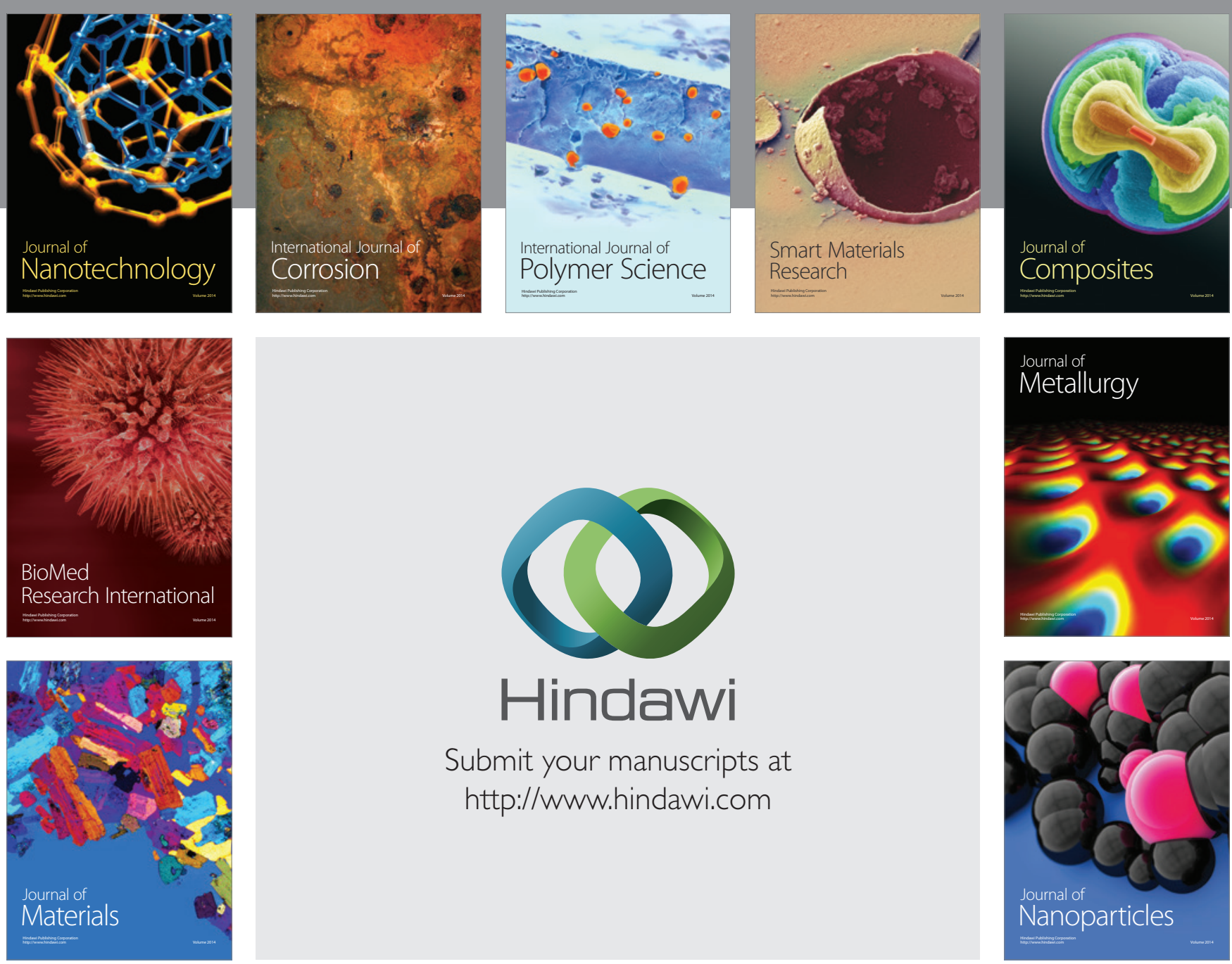

Submit your manuscripts at http://www.hindawi.com
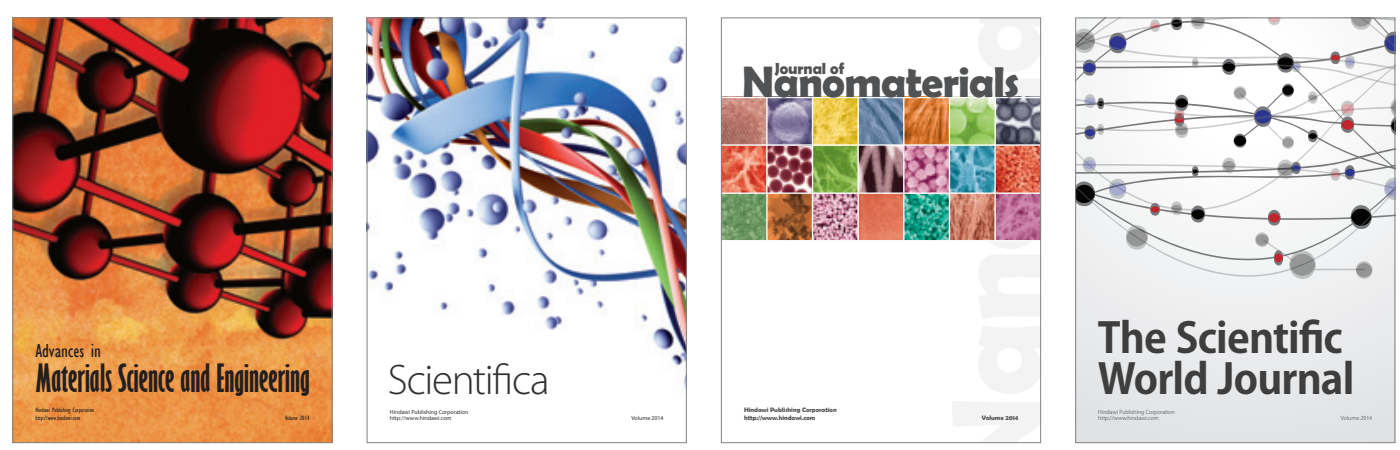

\section{The Scientific World Journal}
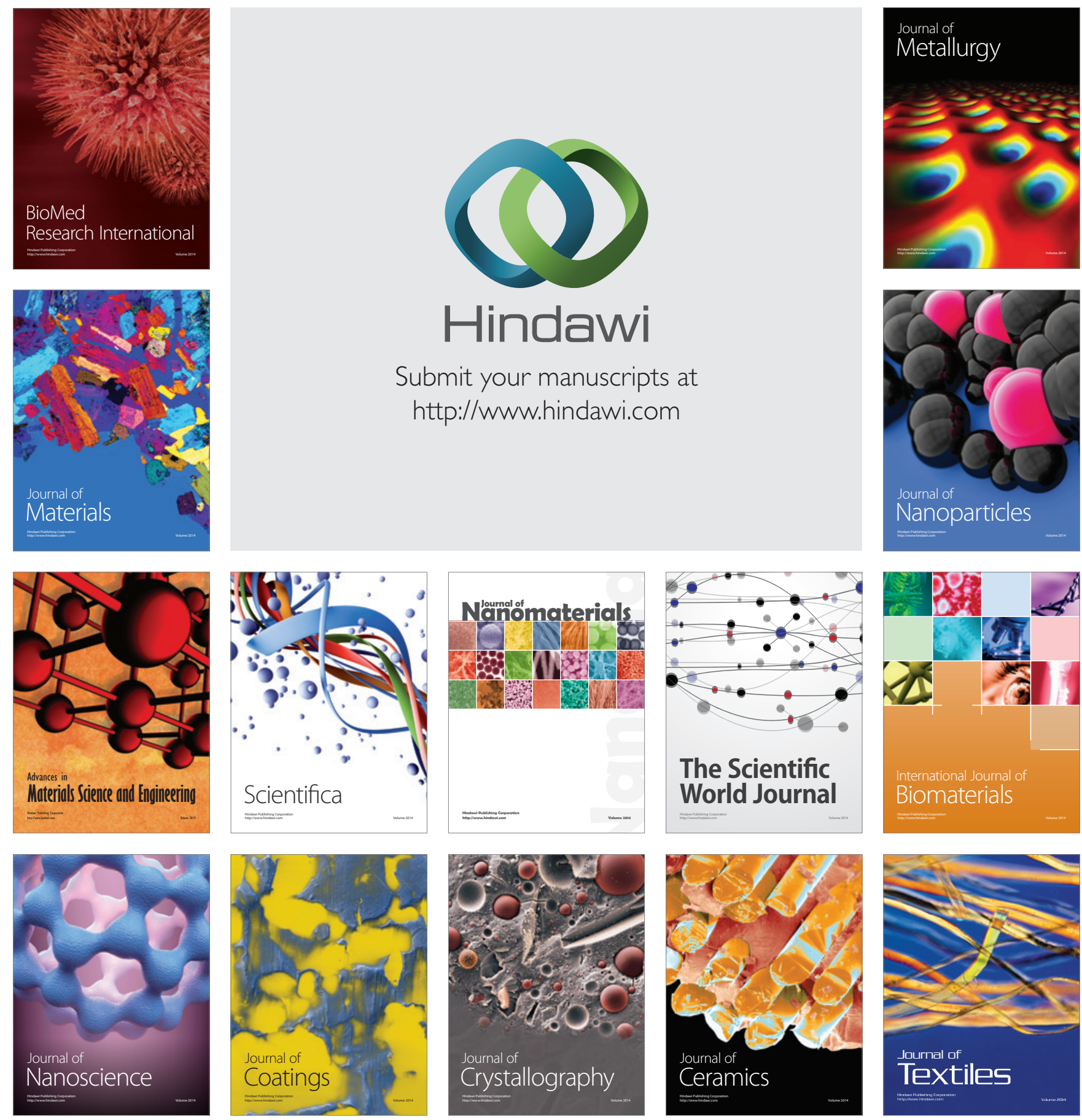